\title{
DEVELOPMENT OF PROCEDURE FOR THE ASSESSMENT OF COGNITIVE COMPLEXITY OF STOICHIOMETRIC TASKS
}

\author{
Saša Horvat ${ }^{*}$, Mirjana D. Segedinac, Dušica D. Milenković, Tamara N. Hrin \\ Faculty of Sciences, University of Novi Sad, Trg Dositeja Obradovića 3, 21000 Novi Sad, Serbia \\ sasa.horvat@dh.uns.ac.rs \\ The aim of this study was the creation of a procedure for determining the cognitive complexity of \\ stoichiometric tasks and its validation. The created procedure included an assessment of the difficulty of \\ concepts and skills, and an assessment of the concepts' interactivity. There were 82 students who \\ participated in the study, with an educational profile of a pharmaceutical technician. As a research \\ instrument for assessing performance, test of knowledge was used. Each task in the test was followed by a \\ seven-point Likert scale for the evaluation of invested mental effort. The validity of this instrument for \\ the assessment of cognitive complexity was confirmed by a series of linear regression analysis where \\ extremely high values of correlation coefficients are obtained among the examined variables: student's \\ performance and invested mental effort (dependent variables) and cognitive complexity (independent \\ variable).
}

Key words: mental effort; performance; problem-solving; stoichiometry

\section{РАЗВОЈ НА ПОСТАПКА ЗА ПРОЦЕНА НА КОГНИТИВНА СЛОЖЕНОСТ НА СТЕХИОМЕТРИСКИТЕ ЗАДАЧИ}

\begin{abstract}
Целта на ова испитување е создавање на постапка за определување на когнитивната сложеност на стехиометриските задачи и нејзина валидација. Разработената постапка вклучува процена на тежината на концептите и вештините и процена на интерактивност на концептите. Во испитувањето беа вклучени 82 студенти со образовен профил фармацевтски техничар. Како истражувачки инструмент за процена на перформансите беше употребен тест на знаење. Секоја задача во тестот беше следена на скалата на Likert од седум точки за евалуација на вложениот ментален труд. Валидноста на овој инструмент за процена на когнитивната сложеност беше потврдена со серија анализи со линеарна регресија со кои беа добиени многу високи вредности на коефициентот на корелација меѓу испитуваните променливи: перформансите на студентите и вложениот ментален труд (зависно променливи) и когнитивна сложеност (независно променлива).
\end{abstract}

Клучни зборови: ментален труд; перформанси; решавање на проблеми; стехиометрија

\section{INTRODUCTION}

There are several reasons why chemistry is considered a difficult subject to teach and learn. Namely, chemistry is an abstract science, and chemical concepts are unintuitive by nature. Furthermore, materials are often presented in the form of lectures with many students not understanding the meaning of the words used during lectures, because chemists readily use a specific language that can be a barrier to the understanding of chemical concepts [1].

Certain chemical concepts, which are studied at the secondary school level, constitute the basis for the establishment of correct correlations with other subjects (mathematics, biology, and physics); one of 
these chemical areas is stoichiometry. It is one of the basic and core areas of chemistry, which requires students' problem solving skills. However, students consider this area difficult, abstract and unattractive [2], because solving stoichiometric problems and mastering stoichiometric concepts requires skills, such as writing and balancing chemical equations, and the quantitative chemical calculations of mass, volume, quantity, number of particles and others [3]. In addition, the complexity of calculations, requiring mathematical skills and the transformation of text into procedural steps, contributes to the unpopularity of stoichiometry as well [4].

Students have a negative attitude towards and fear of stoichiometry [5]; its study is followed by the formation of a number of misconceptions in this area. Namely, Dahsan and Coll [6] identified the students' misconceptions which are closely related to stoichiometry and found that students had a problem with understanding scientific concepts since they do not differ between macroscopic and submicroscopic levels of knowledge representation. It was found that students are under the delusion that one molecule is equal to one mole, or that, under standard conditions, one mole of the substance occupies the same volume, regardless of the physical state of the substance. The same authors suggested that students have had difficulties with the concepts of relative atomic and molecular mass in stoichiometric problems because they consider relative atomic and molecular mass to represent the mass of an atom and a molecule, respectively. They also identified students' problems regarding the concept of a mole, which is essential for almost all calculations in stoichiometry, the concentration of a solution, chemical equations and quantitative relationships in chemical reactions. Many years before, Duncan and Johnstone [7] reported their findings that difficult topics were Avogadro's number of particles, volumetric calculations involving molarities and stoichiometric calculations when proportions were not 1:1. Astudillo and Niaz [8] reported that students achieved better results when given and requested substances were expressed in moles than when they were expressed in units of mass. Finley et al. [9] have identified the concept of mole, oxidation-reduction reactions and stoichiometric calculations as the most difficult concepts in chemistry. The same authors reported that the concept of solution, which is frequently present in stoichiometric tasks, is at the top of the list in difficulty. Ngu and Yeung [10] noted that students' errors in problems with solutions were a combination of a lack of proper understanding of both mathematical and chemical concepts. For students, the concept of concentration is very similar to the concept of density. They consider that mass concentration is a mass per unit volume, without properly understanding what the mass is related to: the mass of solute or the mass of solution [11]. In addition, students have problems with converting units, as well as with algebraic transformation skills. Hence, all of the above research show that students experience difficulties related to stoichiometry, which undoubtedly affect the tasks' performance [12].

Previous research in the field of stoichiometry revealed that there is a significant relationship between students' performance realized on stoichiometric tasks and their working memory capacity, which is indicated by a moderately high correlation coefficient of 0.52 obtained in Karuppiah's study [13]. This research has found that the increase in students' performance requires a reduction of working memory load, which can be achieved by implementing effective methods and strategies of problem solving. That could be achieved by organizing incoming information into schemes in the long-term memory. This includes strategies of information "chunking" that will help students to keep resources free for information processing, that is, to maintain the total load of working memory within the limits of its capacity. Limited capacity of working memory has been well known in the literature, ever since Miller [14] summarized the observations that people can hold a maximum of $7 \pm 2$ pieces of information in their working memory. This result was also confirmed in chemistry. Johnstone [15] first found a strong negative correlation $(r=-0.80)$ between performance and the amount of information needed to solve the task. After that, Johnstone and El-Banna [16] obtained similar results by observing the dependence of performance on the number of steps needed to solve the task. Later studies have also shown that working memory capacity is an important factor which reflects not only performance, but also a greater understanding and used reasoning strategies in chemistry problem solving [17]. The basic assumption that the working memory has limited capacity and that its overload inhibits learning, was the basis for setting up the Theory of cognitive load [18].

Cognitive load is a multidimensional concept, which consists of three measurable components: mental load, mental effort [19] and performance [20]. Mental load is related to teaching parameters, mental effort to the available capacity of working memory that is assigned to the task requirements, while the performances are students' achievements. 
Since the manipulations in mental load will only have an influence on the effect of the teaching process if the student is motivated to invest mental effort in problem solving, it is considered that the mental effort is actually the indicator of the real cognitive load [19].

Another indicator of cognitive load, quite often mentioned in the literature, is cognitive complexity. Bieri [21] was the first to introduce the concept of cognitive complexity which reflects a high degree of differentiation of construct systems among individuals. In his work, Campbell [22] stated how the complexity could be conceptualized - it is associated with the task's characteristics that increase information load, as well as with the information diversity in the task. According to Burleson and Caplan [23] (cited in [24]) cognitive complexity is associated with the content properties, and the basic structure of the cognitive system. Nadolski et al. [25] divided the task complexity construct into two components that can be regarded as objective (the result of the task characteristics) and subjective complexity (determined by both task and task solver characteristics). Maynard and Hakel [26] found excellent reliability (0.904) between objective and subjective complexity, which means that a higher level of objective complexity results in higher level of subjective complexity. Lee and Heyworth [27] presented the cognitive difficulty of a problem as complexity, and concluded that the students' perceptions of complexity roughly correspond to the cognitive difficulty of the problem. Robinson [28] performed a study which showed that cognitive complexity had a significant impact on students' perception of task difficulty. With increasing complexity, stress increases, while motivation and interest stay unchanged. In his research, Johnstone [29] noted that with increasing complexity, which is calculated as the sum of "chunks" of the information given in the task, the percentage of correct answers decreases.

A valid and reliable instrument for assessing the cognitive complexity of chemistry tasks was developed by Knaus et al. [30]. This instrument provides the quantification of cognitive demands of chemistry tasks.

Determination of the cognitive complexity of a task using this instrument is a four-step process: Counting the number of concepts or skills in tasks, assignment of rating (easy, medium or difficult), usage of a rubric for the determination of numerical cognitive complexity rating, and an estimation of interactivity. Following this procedure, a numerical value of the objective complexity is obtained. Knaus et al. [30] proposed this method for ACS general chemistry practice exams, and later modified this instrument and used it on organic chemistry items [31].

A created rubric presents a good method for calculating the complexity of tasks as it decreases the subjectivity of experts in calculating the numerical values of cognitive complexity. However, it is not simple to develop a universal rubric. Therefore, it is necessary to develop rubrics for certain areas of chemistry and levels of education. In addition, it is necessary to further develop rubrics with a detailed analysis of the basic concepts and to introduce additional concepts, specific for the topic.

Stoichiometry is a unique topic of chemistry, which is present in almost all chemistry subjects. It contains many specific types of problems, indicating the need for the development of procedures that will take into account additional concepts.

\section{EXPERIMENTAL SECTION}

\subsection{Aim of the research}

The aim of this study was to create a procedure for determining the cognitive complexity of stoichiometric tasks, and to validate this procedure.

The specific research objectives for determining cognitive complexity are:

- The construction of a table for assessing the difficulty of concepts needed for the assessment of cognitive complexity of stoichiometric tasks;

- The construction of a table for assessing interactivity;

- Combining a constructed table for assessing the difficulty of concepts with a cognitive complexity rating rubric proposed by Knaus et al. [30];

- The assessment of concept interactivity in tasks;

- Determination of the cognitive complexity of the analyzed tasks.

The specific research objectives for validation of the procedure are:

- Correlation of students' performances with cognitive complexity;

- Correlation of students' evaluation of invested mental effort and cognitive complexity;

- Correlation of students' performances and students' evaluation of invested mental effort.

\subsection{Participants}

There were 82 participants in the study (three classes, Secondary medical school "Dr Andra Jova- 
nović" from Šabac, Serbia) from the educational profile of pharmaceutical technicians. The students were 15-18 years old, and the research was conducted in 2011. The testing was anonymous. Pupils entered self-selected passwords and their average chemistry grade during school. The average class grade was $3.61(\mathrm{SD}=0.36)$ in the five-point grading system. The chemistry curriculum in this educational profile was realized through the following subjects: Chemistry (3 hours per week during the first and second grade), Analytical chemistry (4 hours per week during the second grade), Medical biochemistry (4 hours per week during the third grade), Pharmaceutical chemistry ( 3 hours per week during the third and fourth grade) and Sanitary chemistry (2 hours per week during the fourth grade). It is worth mentioning that all students completed the stoichiometry course within their chemistry lessons.

\subsection{Description of the instruments}

Instrument for assessing performance. As a research instrument, this study included a specifically designed test of knowledge. The time for test solving was limited to three school classes (one class is 45 minutes long). The test contained 20 tasks. Each correctly solved task was scored with one point, so that the maximum possible score in the test was 20 points. The concepts, which were necessary for solving the test tasks, had been acquired in the first grade. These concepts are:

- chemical equation,

- stoichiometric calculation, and

- mixture.

The quality of the test was estimated by considering pre-test and post-test assurance parameters according to the model described in Segedinac et al. [32]. Pre-test assurance parameters were estimated by evaluation of the chemistry education experts: one university professor, two teaching assistants, and one high school chemistry teacher. The experts evaluated the test validity, variety of the test tasks, clarity and meaningfulness of the tasks requirements and length of sentences. In addition, they assessed whether the test was constructed in accordance with the curriculum regulations of selected chemistry courses and recommended textbooks. Post-test assurance parameters will be presented in the results section.

Instrument for assessing invested mental effort. Apart from performance, invested mental effort for each student and each test task was also assessed. Invested mental effort was measured by applying a subjective technique with the use of the Likert rating scale. This technique is based on the assumption that respondents are able to perceive their own cognitive processes and to assess the amount of invested mental effort. Subjective rating scales for measuring mental effort developed by Paas [19] are simple to use and have proven to be extremely reliable, with a reliability coefficient of 0.90. In addition, Paas and Van Merriënboer [33] have found that subjective assessment of the amount of invested mental effort using Likert scales is sensitive to differences in task characteristics, that are expected to have an influence on mental effort (reliability coefficient was 0.82 ). For the mental effort measurement, a great advantage of using the Likert scale is that it requires very little time to administer, and does not interfere with the process of problem solving [34]. According to Kalyuga [35], the most precise rating scales are those with 7 or 9 degrees. Although Knaus et al. [30], on whose results this study relies, used a fivepoint scale, we decided to use a seven-point scale, which proved to be a successful instrument in the assessment of mental effort [36-40]. After each solved or unsolved task, students were asked to evaluate invested mental effort by selecting the appropriate descriptive mark "extremely easy", "very easy", "easy", "neither easy nor difficult", "difficult", "very difficult" and "extremely difficult". During the statistical analysis of the results, descriptors were numerically coded as follows: "extremely easy" - numerical value 1 to "extremely difficult" - numerical value 7 .

The obtained results were analyzed using StatGraphics Centurion XVI and IBM SPSS Statistics 22 software programs.

Table for assessing the difficulty of concepts or skills. Knaus et al. developed a cognitive complexity rating rubric (see Knaus et al. [30], p. 555), which has proven to be very reliable. This rubric is based on the addition of the concepts' difficulty or skills needed to solve the task by considering their mutual interactions in order to obtain numerical values of cognitive complexity rating. However, in the case of stoichiometry, this estimation could be difficult. To ensure objectivity when assessing the difficulty of concepts, the authors of this paper have developed Table for the assessment of difficulty of concepts or skills needed to solve stoichiometric problems (Table 1) in which chemical equations, stoichiometric calculations and mixtures are represented. All of these concepts were further structured according to Table 1 . In this table, the most common stoichiometry concepts are presented. At the beginning, each concept was estimated by its difficulty as easy, medium or difficult, which was followed by the determination of cognitive complexity of the problem by sum- 
ming up the difficulty of these concepts using the rubric developed by Knaus et al. [30].

All stoichiometric tasks include the concept of the equation of chemical reaction. There were three possible types of chemical equation concept included in the task:

1. Tasks containing a chemical non-oxidation-reduction reaction equation without coefficients (easy).

2. Tasks containing a chemical oxidationreduction reaction equation without coefficients (medium).

3. A student needing to write oxidationreduction reaction equations and determine the coefficients (difficult).

The following concept included in stoichiometric tasks was the concept of stoichiometric calculations. Namely, given and required substances can be expressed in the same physical quantity (easy), in the physical quantity amount (mole): $x$ (medium), and finally in a different physical quantity except for amount (difficult). Another very common concept present in stoichiometric tasks is concept of mixture. If this concept is present, the following two cases are considered. When the given or required substance is mixture and expressed through quantitative composition (for example mass fraction), the concept is considered easy. On the other hand, the concept is considered difficult when both given and required substances are mixtures and are expressed as different quantitative physical quantities (given substance is expressed through mass concentration and required substance is expressed through mass fraction).

Stoichiometry is conceptually complex besides these basic concepts of chemistry (Table 1), it may also include concepts of physics, biology and other natural sciences. These concepts could be found in addition to stoichiometric calculations, such as for instance Archimedes' principle, reactivity series of metals, calculations based on molecular formulas, etc. However, stoichiometric tasks do not need to include these additional concepts, as they are not essential. Their presence in the task results in increased interactivity.

Table for assessing interactivity. Upon evaluation of difficulty rates for various concepts using Table 1, overall cognitive complexity is determined by adding values estimated for interactivity. Interactivity could get a value of 0,1 , or 2 (Table 2). If there are up to two concepts, interactivity is considered nonsignificant and has the value 0 . If there are three concepts within the task, interactivity is basic and has the value of 1 . Finally, if a stoichiometric task contains more than three concepts, interactivity is considered complex and has a value of 2 .

Table 1

Table for assessing difficulty of concepts or skills in stoichiometry problems

\begin{tabular}{|c|c|}
\hline CHEMICAL EQUATION CONCEPT & \\
\hline Determination of the coefficients in non-oxidation-reduction reaction equations & Easy \\
\hline Determination of the coefficients in the given oxidation-reduction reaction equations & Medium \\
\hline Writing oxidation-reduction reaction equations and determination of the coefficients & Difficult \\
\hline \multicolumn{2}{|l|}{ STOICHIOMETRIC CALCULATIONS } \\
\hline $\begin{array}{l}\text { Given and required substances are the same physical quantities (mass:mass, amount:amount, } \\
\text { volume:volume) }\end{array}$ & Easy \\
\hline $\begin{array}{l}\text { Given and required substances are expressed as the following physical quantities, amount: } x \text { ( } \mathrm{x}=\text { volume, } \\
\text { mass, number of particles) }\end{array}$ & Medium \\
\hline $\begin{array}{l}\text { Given and required substances are expresses as different physical quantities excluding amount } \\
\text { (mass:volume, mass:number of particles) }\end{array}$ & Difficult \\
\hline \multicolumn{2}{|l|}{ MIXTURE CONCEPT } \\
\hline $\begin{array}{l}\text { Given or required substance is mixture and expressed through quantitative composition (mass fraction, } \\
\text { concentration and mass concentration) }\end{array}$ & Easy \\
\hline $\begin{array}{l}\text { Given and required substances are mixtures and expressed as various physical quantities (mass fraction } \\
\text { and mass concentration) }\end{array}$ & Difficult \\
\hline
\end{tabular}


T a ble 2

Table for assessing interactivity in stoichiometric tasks

\begin{tabular}{lc}
\hline \hline Description & $\begin{array}{c}\text { Interactivity } \\
\text { value }\end{array}$ \\
\hline Task contains up to two concepts & 0 \\
Task contains three concepts & 1 \\
Task contains more than three concepts & 2 \\
\hline \hline
\end{tabular}

\section{RESULTS AND DISCUSSION}

This procedure provides a method for easier assessment complexity of stoichiometric tasks. The principle of using this procedure is a very simple and objective. We are going to explain the procedure of calculating the cognitive complexity of one simple and one more complex task.

As an example of simple task, we suggested task number 9:

Calculate the volume of carbon monoxide (STP), which is produced from the oxidation of 3.6 $g$ of carbon by the following chemical equation:

$$
2 \mathrm{C}+\mathrm{O}_{2} \rightarrow 2 \mathrm{CO} .
$$

In the first step, it is necessary to calculate the number of concepts and their difficulty according to Table 1. This task contains one concept - the concept of stoichiometric calculation. In this task, given and required substances are expressed as different physical quantities (mass : volume). In accordance with Table 1, this concept is difficult.

According to the rubric from Knaus et al. [30], the cognitive complexity of the task, which contains one difficult concept, has a rating value of 4. Since this task contains only one concept, according to Table 2, interactivity is nonsignificant and has a value of 0 .

Hence, the overall cognitive complexity of this task is $4+0=4$.

As an example of a complex task, we suggested task number 20:

A sample of aluminum and copper alloy has a density of $1.13 \mathrm{~g} \mathrm{~cm}^{-3}$. Inserting the sample into the beaker with distilled water, the level of water increases by $9.70 \mathrm{~cm}^{3}$. Dissolving the sample in hydrochloric acid releases $6.72 \mathrm{dm}^{3}$ of hydrogen measured under STP. Calculate the percentage of aluminum in the alloy. The reactivity series of metals table is given below.

K, Na, Ca, Mg, Al, Zn, Cr, Fe, Cd, Co, Ni, Sn, $\mathrm{Pb}, \mathrm{H}, \mathrm{Cu}, \mathrm{Hg}, \mathrm{Ag}, \mathrm{Pd}, \mathrm{Pt}, \mathrm{Au}$
Using the Table 1 it is determined that this task contains three basic concepts:

1. Concept of chemical equation which is difficult (students need to write and balance oxidoreduction equation);

2. Concept of stoichiometric calculations which is difficult (given and required substances are given in the relation mass : volume);

3. Concept of mixture which is easy (required substance should be expressed as mass fraction).

According to the rubric from Knaus et al. [30], the cognitive complexity of the task which contains 2 difficult and 1 easy concepts has a rating value of 6 .

Besides these three basic concepts, this task contains two additional concepts: Archimedes' principle and reactivity series. Since the number of concepts in the task is 5 , the interactivity is complex and has a value of 2 . Therefore, the overall complexity of this task is 8 .

In the same manner, the values of cognitive complexity have been calculated for all tasks, the results of which are summarized in Table 3.

Table 3

\section{Cognitive complexity ratings of stoichiometric tasks}

\begin{tabular}{cc}
\hline \hline Cognitive complexity rating & Task number \\
\hline 1 & $1,7,14$ \\
2 & 2,15 \\
3 & 4,16 \\
4 & $3,8,9,10,18$ \\
5 & 11,17 \\
6 & 12,19 \\
7 & 5,13 \\
8 & 6,20 \\
\hline \hline
\end{tabular}

\subsection{Procedure validation}

The created test, which was used in this study, showed satisfactory metric properties. The reliabilities for performance and mental effort expressed by Cronbach $\alpha$ coefficients were calculated as a measure of internal consistency. The value of 0.83 for performance and 0.92 for mental effort indicated an excellent reliability of the applied test. The calculated indices of item difficulty are in the range from $2.44 \%$ to $93.90 \%$. The average value is $53.66 \%$, and the test was characterized as moderately difficult. Five tasks 
have an index difficulty less than $30 \%$, which makes them difficult, while eight tasks have an index of difficulty greater than $70 \%$, which make them easy tasks to solve. Discrimination indices are in the range from 0.09 to 0.86 . The average value is 0.49 and presents an excellent discrimination index. Fifteen tasks have an excellent discrimination index greater than 0.40 , while only two have a poor discrimination index (between 0.00 and 0.19 ), so it should be revised for further use [41]. The applied test was characterized by basic statistical parameters, which are shown in Table 4.

\section{Table 4}

Descriptive statistics for the students' performance and mental effort

\begin{tabular}{lcc}
\hline \hline Parameter & $\begin{array}{c}\text { Students' } \\
\text { performance } \\
(\mathrm{N}=82)\end{array}$ & $\begin{array}{c}\text { Students' ratings } \\
\text { of mental effort }^{2} \\
(\mathrm{~N}=82)\end{array}$ \\
\hline Average & 10.73 & 3.87 \\
Standard deviation & 4.06 & 0.67 \\
Minimum & 0.00 & 1.70 \\
Maximum & 20.00 & 5.55 \\
Range & 20.00 & 3.85 \\
\hline \hline
\end{tabular}

${ }^{1}$ Students' performances could be ranged from 0 to 20

${ }^{2}$ Possible ratings for invested mental effort could be ranged from 1 to 7: extremely easy (1) to extremely difficult (7)

The average value of students' performances on the constructed test was 10.73 , with the standard deviation of 4.06. The average value of students' mental effort on the test was 3.87 with a standard deviation of 0.67 .

The validity of the Procedure created for this study was confirmed by a statistically significant correlation between students' performances and cognitive complexity, as well as between students' evaluation of invested mental effort and cognitive complexity. Therefore, the first linear regression analysis was done by observing the dependence of students' performances, as the dependent variable, and cognitive complexity, as an independent variable. The results of this analysis are presented graphically in Figure 1 and in Table 5.

The coefficients obtained by regression analysis $(r=-0.88 ; p=0.00)$ indicate a very strong correlation between the students' performances and cognitive complexity. The negative value of the correlation coefficient indicates that an increase in complexity causes a decrease in performance. It is important to mention that in correlation analysis, students' performances were calculated as an average value of the performances of all students for the tasks. Values of the task cognitive complexity on the constructed test were in the range from 1 to 8 . Since the test has twenty tasks, there were tasks with the same value of cognitive complexity. In tasks with the value of cognitive complexity 1 , the values of performance are very high $(0.84,0.91$ and 0.84$)$. On the other hand, there were two tasks (No. 20 and No. 6) with the value 8 for cognitive complexity, and the average performance was only 0.02 for task No. 20, and 0.06 for task No. 6.

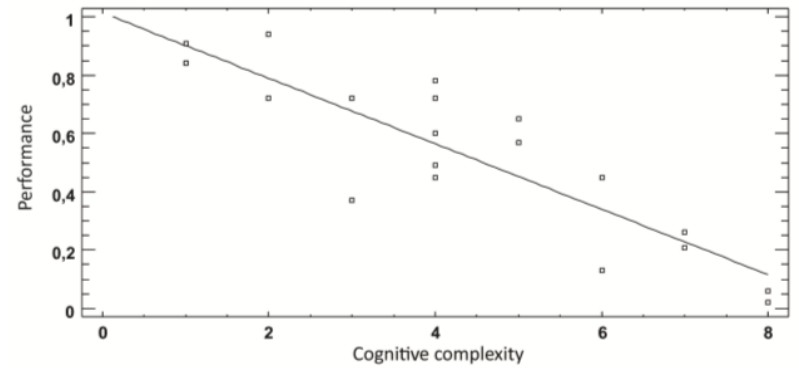

Fig. 1. Correlation of students' performances with cognitive complexity

Table 5

Statistical parameters of the regression analysis of students' performances and cognitive complexity

\begin{tabular}{lc}
\hline \hline Parameter & Value \\
\hline The correlation coefficient & -0.88 \\
$R$-square & $77.81 \%$ \\
$P$-value & 0.00 \\
Equation & Performance $=1.01-0.11$ \\
& $\times$ Cognitive complexity \\
\hline
\end{tabular}

In the second part of the regression analysis, the dependence of the students' mental effort from cognitive complexity of the task was observed. Results of the regression analysis are presented graphically in Figure 2 and tabulated in Table 6.

The resulting correlation coefficient $(r=$ $0.92 ; p=0.00)$ indicates a very strong correlation between the dependent variable, mental effort, and the independent variable, cognitive complexity. The positive value of this coefficient shows that with increased cognitive complexity, students have to use more resources of their working memory, and thus have to invest more mental effort to solve the task. This is consistent with the findings of Pollock et al. [38] and Sweller and Chandler [42], who concluded that with increasing complexity of the tasks, information processing in working memory 
becomes less efficient due to the imposition of greater demands, resulting in higher mental effort ratings.

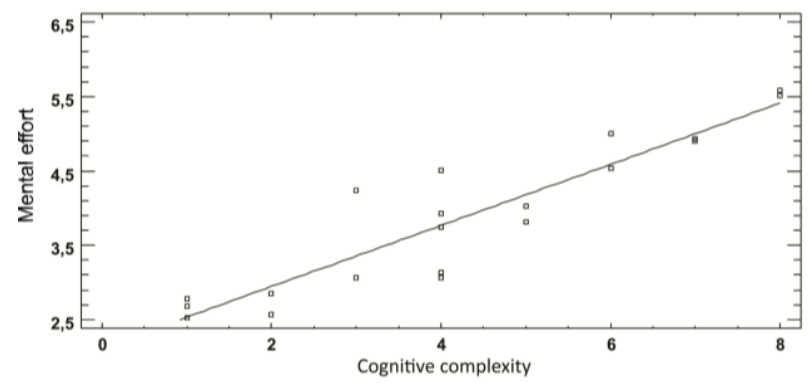

Fig. 2. Correlation of students' evaluation of invested mental effort and cognitive complexity

Table 6

Statistical parameters of the regression analysis of student evaluation of invested mental effort and cognitive complexity

\begin{tabular}{lc}
\hline \hline Parameter & Value \\
\hline The correlation coefficient & 0.92 \\
$R$-square & $84.59 \%$ \\
$P$-value & 0.00 \\
Equation & Mental effort $=2.12+0.41$ \\
\hline \hline
\end{tabular}

After we confirmed the validity of the procedure, and obtained empirical evidence of the linear dependence between the mean values of performance, and mental effort as a dependent variable and cognitive complexity as an independent variable, the third part of the linear regression included consideration of the relationship between students' performances and students' assessments of invested mental effort. The results are shown graphically in Figure 3 and summarized in Table 7.

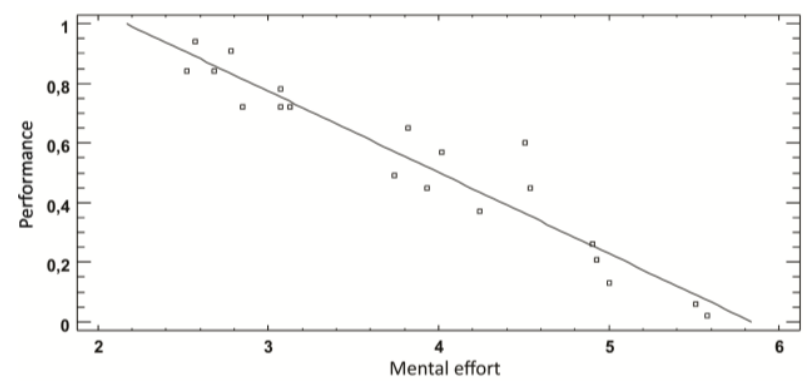

Fig. 3. Correlation of students' performances and students' evaluation of invested mental effort
T a ble 7

Statistical parameters of the regression analysis of students' performances and students' evaluation of invested mental effort

\begin{tabular}{lc}
\hline \hline Parameter & Value \\
\hline The correlation coefficient & -0.95 \\
$R$-square & $91.25 \%$ \\
$P$-value & 0.00 \\
Equation & Performance $=1.59-0.27$ \\
& $\times$ Mental effort \\
\hline \hline
\end{tabular}

This dependence is described with a very strong correlation $(r=-0.95 ; p=0.00)$ and high $R$ square value. The existence of a significant correlation between performance and mental effort has already been confirmed in earlier studies by Knaus et al. [43], Knaus et al. [30], Murphy [44] and Raker et al. [31]. The significance of this created procedure is reflected by exactly defining cognitive complexity of stoichiometric tasks. This procedure could help teachers to facilitate dimensioning of complexity of the stoichiometric problems during tasks construction. First, it is necessary that teachers know all of the concepts that may be present in stoichiometric problems, as well as the relations among them. By using the procedure, the teacher can gradually make stoichiometry problems more complex, thus providing development of problemsolving skills. The design of the tasks of various levels of complexity is a way to better assess learning results.

\section{CONCLUSION, LIMITATIONS AND IMPLICATIONS FOR FURTHER RESEARCH}

In this study, a procedure for assessing the cognitive complexity of stoichiometric problems has been developed. This procedure can be further implemented in the classroom. It allows teachers to create tasks of optimal complexity, starting from an equation of a chemical reaction, over the number of various basic stoichiometric calculations, until computation with the impure substances or solutions. The largest contribution of the created procedure is that it is designed to show an objective value of cognitive complexity in the domain of stoichiometry. This study can act as a potential method for constructing and evaluating future procedures for the assessment of a tasks cognitive complexity in other chemistry courses and topics. Dimensioning complexity can better predict student's success. It can enable teachers to take into account the numerical values of cognitive 
complexity of the tasks to avoid cognitive overload of the students' working memory.

The limitation of this study could be found in the sample of respondents. Namely, the tested students attended only one school and had a single educational profile. Table 1 could therefore not predict all of the additional concepts that may occur. Therefore, in further research, additional concepts should be specified in more detail. A wide range of complex problems can be created in chemistry, which requires skills and concepts needed to solve them, and following that, procedures need to be created to assess their difficulty.

Acknowledgements. Presented results are part of the research conducted within the Project "Infrastructure for electronic supported learning in Serbia". Grant No. 47003 of the Ministry of Education, Science and Technological Development of the Republic of Serbia.

\section{REFERENCES}

[1] L. Cardellini, Chemistry: Why the subject is difficult?, Educ. Quim., 23(E2), 305-310 (2012).

[2] H. J. Schmidt, C. Jignéus, Students' strategies in solving algorithmic stoichiometry problems. Chem. Educ. Res. Prac., 4(3), 305-317 (2003).

DOI: $10.1039 / \mathrm{B} 3 \mathrm{RP} 90018 \mathrm{E}$

[3] J. Molnár, L. Molnár-Hamvas, LEGO-method - new strategy for chemistry calculation. US-China Education Review B, 7, 891-908 (2011).

[4] E. P. Wagner, A study comparing the efficacy of a mole ratio flow chart to dimensional analysis for teaching reaction stoichiometry. Sch. Sci. Math., 101(1), 10-22 (2011). DOI: 10.1111/j.1949-8594.2001.tb18185.x

[5] R. M. Felder, Stoichiometry without tears. Chem. Eng. Educ., 24(4), 188-196 (1990).

[6] C. Dahsah, R. K. Coll, Thai grade 10 and 11 students' understanding of stoichiometry and related concepts, Int. J. of Sci. and Math. Educ., 6(3), 573-600 (2008). DOI: $10.1007 / \mathrm{s} 10763-007-9072-0$

[7] I. M. Duncan, A. H. Johnstone, The mole concept in chemistry. Educ. Chem., 10(6), 213-215 (1973).

[8] L. Astudillo, M. Niaz, Reasoning strategies used by students to solve stoichiometry problems and its relationship to alternative conceptions, prior knowledge, and cognitive variables, J. Sci. Educ. Technol. 5(2), 131-140 (1996). DOI: 10.1007/BF01575153

[9] F. N. Finley, J. Stewart, W. L. Yarroch, Teachers' perceptions of important and difficult science content, Sci. Educ., 66(4), 531-538 (1982). DOI: $10.1002 /$ sce.3730660404

[10] B. H., Ngu, A. S. Yeung, Algebra word problem solving approaches in a chemistry context: Equation worked examples versus text editing, J. Math. Behav., 32(2), 197-208 (2013). DOI: 10.1016/j.jmathb.2013.02.003

[11] R. M. Heyworth, Procedural and conceptual knowledge of expert and novice students for the solving of a basic problem in chemistry, Inter. J. Sci. Educ., 21(2), 195211 (1999). DOI: 10.1080/095006999290787
[12] S. BouJaoude, H. Barakat, Secondary school students' difficulties with stoichiometry, Sch. Sci. Rev., 81(296), 91-98 (2000).

[13] N. Karuppiah, Solving stoichiometric problems: Do we really understand our students?, CoSMed 2007, Penang, Malaysia. Retrieved from http://www.recsam.edu.my/ cosmed/cosmed07/abstractsfullpapers2007/SCIENCE/ S029F.pdf Accessed June 2014.

[14] G. A. Miller, The magical number seven, plus or minus two: Some limits on our capacity for processing information, Psychol. Rev., 63(2), 81-97 (1956). DOI: $10.1037 / \mathrm{h} 0043158$

[15] A. H. Johnstone, New stars for the teacher to steer by? J. Chem. Educ., 61(10), 847-849 (1984). DOI: $10.1021 / \mathrm{ed} 061 \mathrm{p} 847$

[16] A. H. Johnstone, H. El-Banna, Understanding learning difficulties a predictive research model. Stud. High. Educ., 14(2), 159-167 (1989). DOI: $10.1080 / 03075078912331377486$

[17] M. Niaz, Reasoning strategies of students in solving chemistry problems as a function of developmental level, functional M-capacity, and disembedding ability. Inter. J. Sci. Educ., 18(5), 525-542 (1996).

DOI: $10.1080 / 0950069960180503$

[18] J. Sweller, Cognitive load during problem solving: Effects on learning, Cognitive Sci., 12(2), 257-285 (1988). DOI: 10.1016/0364-0213(88)90023-7

[19] F. Paas, Training strategies for attaining transfer of problem-solving skill in statistics: A cognitive-load approach, J. Educ. Psychol., 84(4), 429-434 (1992). DOI: $10.1037 / 0022-0663.84 .4 .429$

[20] F. Paas, J. J. G. van Merriënboer, Instructional control of cognitive load in the training of complex cognitive tasks, Educ. Psychol. Rev., 6(4), 51-71 (1994). DOI: $10.1007 / \mathrm{BF} 02213420$

[21] J. Bieri, Cognitive complexity-simplicity and predictive behaviour, J. Abnorm. Soc.l Psych., 51(2), 263-268 (1955). DOI: $10.1037 / \mathrm{h} 0043308$

[22] D. J Campbell, Task complexity: A review and analysis, Acad. Manage. Rev., 13(1), 40-52 (1988). DOI: $10.5465 / A M R .1988 .4306775$

[23] B. R. Burleson, S. E. Caplan, Cognitive Complexity, in Communication and personality: Trait perspectives, J. C. McCroskey, J. A. Daly \& M. M. Martin (Eds.), Cresskill, NJ: Hampton, 1998, pp. 230-286.

[24] V. Benet-Martínez, F. Lee, J. Leu, Biculturalism and cognitive complexity: Expertise in cultural representations, J. Cross. Cult. Psychol., 37(4), 386-407 (2006). DOI: $10.1177 / 0022022106288476$

[25] R. J. Nadolski, P. A. Kirschner, J. J. G. van Merriënboer, J. Wöretshofer, Development of an instrument for measuring the complexity of learning task, Educ. Res. Eval., 11(1), 1-27, (2005). DOI: $10.1080 / 13803610500110125$

[26] D. C. Maynard, M. D. Hakel, Effects of objective and subjective task complexity on performance, Hum. Perform., 10(4) 303-330 (1997).

[27] F. L. Lee, R. Heyworth, Problem complexity: A measure of problem difficulty in algebra by using computer. Educ. J., 28(1), 85-107 (2000). 
[28] P. Robinson, Task complexity, task difficulty, and task production: Exploring interactions in a componential framework, Appl. Linguist., 22(1), 27-57, (2001). DOI: 10.1093/applin/22.1.27

[29] A. H. Johnstone, Chemical education research in Glasgow in perspective. Chem. Educ. Res. Pract., 7(2), 49-63, (2006). DOI: 10.1039/B5RP90021B

[30] K. Knaus, K. Murphy, A. Blecking, T. Holme, A valid and reliable instrument for cognitive complexity rating assignment of chemistry exam items, J. Chem. Educ., 88(5), 554-560 (2011). DOI: 10.1021/ed900070y

[31] J. R. Raker, J. M. Trate, T. A. Holme, K. Murphy, Adaptation of an instrument for measuring the cognitive complexity of organic chemistry exam items, J. Chem. Educ., 90(10), 1290-1295 (2013). DOI: $10.1021 / \mathrm{ed} 400373 \mathrm{c}$

[32] M. Segedinac, M. Segedinac, Z. Konjović, G. Savić, A formal approach to organization of educational objectives, Psihologija, 44(4) 307-323, (2011).

[33] F. G. W. C. Paas, J. J. G. van Merriënboer, Variability of worked examples and transfer of geometrical problemsolving skills: A cognitive-load approach, J. Educ. Psychol., 86(1),122-133 (1994).

DOI: $10.1037 / 0022-0663.86 .1 .122$

[34] P. Ayres, F. Paas, Cognitive load theory: New directions and challenges, Appl. Cognitive Psych., 26(6), 827-832 (2012). DOI: 10.1002/acp.2882

[35] S. Kalyuga, Managing cognitive load in adaptive multimedia learning, Information Science Reference, New York (2009).

[36] P. Ayres, Using subjective measures to detect variations of intrinsic cognitive load within problems, Learn. Instr., 16(5), 389-400 (2006).

DOI: 10.1016/j.learninstruc.2006.09.001
[37] B. H. Ngu, E. Mit, F. Shahbodin, J. Tuovinen,. Chemistry problem solving instruction: a comparison of three computer-based formats for learning from hierarchical network problem representations, Instr. Sci., 37(1), 21-42 (2009). DOI: 10.1007/s11251-008-9072-7

[38] E. Pollock, P. Chandler, J. Sweller, Assimilating complex information, Learn. Instr., 12(1), 61-86 (2002). DOI: $10.1016 / \mathrm{S} 0959-4752(01) 00016-0$

[39] D. Milenković, M. Segedinac, T. Hrin, Increasing high school students' chemistry performance and reducing cognitive load through an instructional strategy based on the interaction of multiple levels of knowledge representation, J. Chem. Educ., 91(9), 1409-1416 (2014).

[40] D. Milenković, M. Segedinac, T. Hrin, S. Cvjetićanin, Cognitive load at different levels of chemistry representations, Croat. J. Educ., 16(3), 699-722 (2014).

[41] S. S. Pande, R. P. Pande, V. P. Parate, A. N. Nikam, S. H. Agrekar, Correlation between difficulty and discrimination indices of MCQs in formative exam in physiology, SE. Asian J. Med. Educ., 7(1), 45-50 (2013).

[42] J. Sweller, P. Chandler,. Why some material is difficult to learn, Cognition Instruct., 12(3), 185-253 (1994). DOI: $10.1207 / s 1532690 x c 11203 \_1$

[43] K. J. Knaus, K. L. Murphy, T. A. Holme, Designing chemistry practice exams for enhanced benefits an instrument for comparing performance and mental effort measures, J. Chem. Educ., 86(7), 827-833 (2009). DOI: $10.1021 / \mathrm{ed} 086 \mathrm{p} 827$

[44] K. Murphy, Using a personal response system to map cognitive efficiency and gain insight into a proposed learning progression in preparatory chemistry, J. Chem. Educ., 89(10), 1229-1235 (2012). DOI: $10.1021 / \mathrm{ed} 100859 \mathrm{n}$ 